\title{
Prevalence of mesquite (prosopis species) allergy and efficacy of conventional allergen specific Immunotherapy (ASIT) to mesquite in Egyptian patients with perennial allergic rhinitis (PAR)
}

\author{
Farag I Farag-Mahmod ${ }^{1,2^{*}}$, Waheed Hessam ${ }^{1}$, Khalil A Khalil ${ }^{1}$ \\ From Canadian Society of Allergy and Clinical Immunology Annual Scientific Meeting 2010 \\ Victoria, Canada. 3-6 November 2010
}

\section{Background}

Mesquite is a genus of leguminous spiny trees and shrubs abundant in the tropical and subtropical deserts. Mesquite pollen is a potent allergen capable of inducing allergy in susceptible individuals living remote from the plant source. This study was conducted on 200 PAR patients in the Suez Canal region of Egypt to determine the prevalence of mesquite allergy and to assess the efficacy of conventional ASIT in these patients.

\section{Subjects, materials and methods}

Two hundred adult PAR patients were evaluated by allergy prick skin testing (PST) against a panel of 15 different aeroallergens including mesquite. Patients exhibiting a positive PST response to mesquite only were subjected to mesquite conventional subcutaneous ASIT. All reagents were purchased from Omega Laboratories, CANADA. Informed consents, symptom and medication scores were obtained before and after ASIT.

\section{Results}

Eighty six patients exhibited a positive PST response to mesquite allergen. Out of these 38 patients were positive to mesquite allergen only. Significant improvement in symptom and medication scores were detected in 24/38 patients 4 months after the initiation of ASIT.

\footnotetext{
* Correspondence: ffarag112@Yahoo.com

${ }^{1}$ Allergy/Immunology Unit, Faculty of medicine, Suez Canal University,

Ismailia 24111, Egypt

Full list of author information is available at the end of the article
}

\section{Conclusions}

Mesquite pollen allergy is common among Egyptian PAR patients and ASIT with mesquite extract can reduce the burden of the disease in these patients.

\section{Author details}

'Allergy/Immunology Unit, Faculty of medicine, Suez Canal University, Ismailia 24111, Egypt. ${ }^{2}$ Omega Laboratories Itd Montreal, QC H3M 3E4, Canada.

Published: 4 November 2010

\section{doi:10.1186/1710-1492-6-S2-P12}

Cite this article as: Farag-Mahmod et al.: Prevalence of mesquite (prosopis species) allergy and efficacy of conventional allergen specific Immunotherapy (ASIT) to mesquite in Egyptian patients with perennial allergic rhinitis (PAR). Allergy, Asthma \& Clinical Immunology 2010 6(Suppl 2):P12.
Submit your next manuscript to BioMed Central and take full advantage of:

- Convenient online submission

- Thorough peer review

- No space constraints or color figure charges

- Immediate publication on acceptance

- Inclusion in PubMed, CAS, Scopus and Google Scholar

- Research which is freely available for redistribution
() Biomed Central 